\title{
UN CONJUNTO DE PUNTAS DE PROYECTIL RECUPERADAS EN LA EXCAVACIÓN DEL CASTRO DE LOS JUDÍOS (PUENTE CASTRO, LEÓN) Y EL USO DE ARCOS Y BALLESTAS EN LA EDAD MEDIA
}

\author{
María GONZÁLEZ CASTAÑóN
}

\begin{abstract}
RESUMEN: El estudio del armamento medieval se ha visto restringido durante años al análisis de piezas de lujo con criterios artísticos. En los últimos años esta tendencia ha ido cambiando y han aparecido diversos trabajos sobre otro tipo de objetos, especialmente puntas de proyectil.

Con este trabajo se pretende aportar una serie de piezas inéditas recuperadas en las excavaciones del Castro de los Judíos (Puente Castro, León) a los materiales publicados hasta la fecha.
\end{abstract}

PALABRAS CLAVE: puntas de proyectil, arco, ballesta.

ABSTRACT: The study of medieval armaments has been restricted for many years to the analysis of luxury pieces with artistic criterion. Recently this trend has been changing and they have appeared different works which deal with other type of objects, especially tips of projectile.

The objective of this essay is to enclose a group of unknown pieces recovered in the excavation called "Castro de los Judíos" (Puente Castro, León) to the material goods published up to date.

KEYWORDS: projectiles, bow, crossbow.

Los trabajos de campo en el Castro de los Judíos ${ }^{1}$, ubicado en Puente Castro (León), se prolongaron entre 1999 y 2005, sacando a la luz una serie de materiales

${ }^{1}$ El Castro de los Judíos se localiza en un cerro amesetado desde el que se divisa toda la ciudad de León y bajo el que discurre el río Torío. En su extremo noroeste se halla un recinto elevado unos cinco metros por encima del nivel del cerro distinguiéndose así dos zonas de hábitat. Las excavaciones han permitido diferenciar dos fases ocupacionales a través del análisis del material cerámico: una primera comprendida entre los siglos IX - XI y una segunda asociada a producciones del siglo XII en adelante. Avello Álvarez, J. L. y SÁnchez - Lafuente, J. (2000 - 2001). "Excavaciones en el poblado del Castro de los Judíos, Puente Castro, León. Campañas 1999 - 2000". Lancia 4, pp. 221 - 227; Avello Álvarez, J. L. y SÁnChez - LAfuente, J. (2003). "El Castro de los Judíos de Puente Castro (León)". En Izquierdo Benito, R. y López Álvarez, A. M (eds.). Juderías y sinagogas en la Sefarad medieval. XI Curso de cultura hispanojudia y sefardi de la Universidad de 
entre los que se contaba un importante volumen de mobiliario metálico que puede proporcionarnos numerosa información sobre las formas de vida, actividades y tecnología de los habitantes del cerro. A lo largo de la Edad Media los metales, en especial el hierro, resultan determinantes en ciertos sectores de la actividad humana como la fabricación de útiles y armas. Precisamente, el material bélico exhumado centra el interés de este trabajo. Durante el proceso de excavación se han registrado más de un centenar de puntas de proyectil vinculadas con el empleo de armas blancas. Para este estudio se ha seleccionado una muestra representativa del total, donde se incluyen todos los tipos registrados, compuesta por 45 piezas correspondientes a la campaña del año 2005 y vinculadas cronológicamente a contextos del siglo XII en adelante ${ }^{2}$.

Las puntas de proyectil se clasifican dentro de lo que se conoce como armamento ofensivo, en oposición al defensivo. Éste último se constituye básicamente por las protecciones corporales empleadas por los diferentes cuerpos del ejército: cascos, escudos, cotas de malla o armaduras ${ }^{3}$. Dichos proyectiles se vinculan con el uso de dos tipos de armas: los arcos y las ballestas, panoplia imprescindible en las llamadas guerras de asedio, enfrentamientos muy usuales en la Edad Media. ${ }^{4} \mathrm{Su}$ uso en esta clase de operaciones, así como en la defensa de ciudades y plazas, las convierte en el armamento más exhumado en las excavaciones de asentamientos fortificados europeos, como veremos más adelante. Su empleo se extenderá a lo largo de toda la Edad Media hasta que se vean desplazadas por las armas de fuego en el siglo XVI.

A pesar de la popularidad de estos instrumentos de guerra en la Edad Media, los elementos del equipo de un arquero o ballestero que podemos estudiar hoy día son limitados. Se restringen a aquellas piezas fabricadas sobre materiales no

Castilla La Mancha. Toledo 2001. Cuenca: Ediciones de la Universidad de Castilla La Mancha, pp. 532 - 555; Martínez PeÑín, R. (2006). Estudio de la cerámica medieval del Castro de los Judíos, Puente Castro (León). Campaña de 1999. (En prensa), p. 51 y p. 225, fig. 72.

2 Ibíd.

3 Se ha preferido denominar con el nombre genérico de puntas de proyectil a las piezas recuperadas ante la indefinición de las mismas respecto a su funcionalidad como punta de flecha (para arco) o como punta de dardo (para ballesta). Se consideró que la finalidad en todo caso era la misma: herir o matar. La mayoría de autores consultados opina que es difícil adscribir las puntas a una u otra arma en esta época.

${ }^{4}$ Podríamos poner el ejemplo de Godofredo V de Anjou que conquistó Normandía entre 1135 y 1145 mediante esta táctica y sin entrar en batalla una sola vez. JONES, R. L. C. (2005). "Fortalezas y asedios en Europa occidental c. 800 - 1450" en Keen, M. (ed.). Historia de la guerra en la Edad Media. Madrid: Antonio Machado Libros, pp. 211 - 212. 
perecederos, lo que nos deja un escaso margen de acción que obliga a acudir a las fuentes escritas y la iconografía, así como a las armas actuales que siguen empleando coleccionistas y aficionados al tiro.

\section{EL USO DE ARCOS Y BALLESTAS EN LA EDAD MEDIA}

El primer elemento del instrumental de todo tirador es el arma en sí. Éstas se construían en distintos tipos de madera fabricándose las cuerdas sobre materias vegetales o animales. Como es de suponer se trata de elementos que no suelen dejar huella en el registro arqueológico, a excepción de casos muy concretos, como el magnífico ejemplar de ballesta nazarí recuperado en las Alpujarras granadinas y conservado en el Museo Arqueológico de Granada ${ }^{5}$.

El empleo del arco en la Prehistoria es un hecho constatado ampliamente. No sólo se han recuperado numerosas puntas de flecha líticas, datadas a partir del Paleolítico Superior, sino que en las pinturas rupestres es frecuente la presencia de arqueros en escenas de caza o bélicas. Sin embargo, la difusión de este arma como instrumento de guerra se vincula al mundo oriental, concretamente a los ejércitos asirios y los pueblos de las estepas euroasiáticas. Durante la Edad Media el arco será el arma favorita de los musulmanes, como nos recuerda el escritor granadino Ibn Hudayl: todo creyente debe aspirar a tener arco y flechas ${ }^{6}$. El arco más empleado en el ámbito cultural islámico, y en general en el mundo oriental, es el llamado arco compuesto, que se constituye de dos piezas de madera ensambladas, reforzadas con cuero en la cara interna y con tendón animal en la externa (vid. fig. 2).

Por otra parte, en la Europa occidental cristiana, el uso de arcos se documenta arqueológicamente desde los siglos VI - VII a través de puntas de flecha para arco asociadas a tumbas merovingias ${ }^{7}$. En algunas zonas del continente como Inglaterra o los países nórdicos será el arma más utilizada por los ejércitos, sobre todo desde la difusión del famoso long bow inglés durante las guerras galesas de la segunda mitad del siglo XIII. La efectividad de este arco radicaba, en buena medida, en las dimensiones de las flechas disparadas que alcanzaban el metro de longitud. Para

${ }^{5}$ Mendoza Eguaras, E., SÁez Pérez, L. y De Santiago Simón, E. (1982). "La ballesta nazarí del Museo Arqueológico de Granada”. Cuadernos de la Alhambra 18, pp. 179 - 184.

${ }^{6}$ Ibn Hudayl lo menciona en alusión a unas palabras de Mahoma en el Corán. IBN HUDAYL. Gala de caballeros, blasón de paladines (ed. preparada por Viguera, $\mathrm{M}^{\mathrm{a}}$ J. (1977). Madrid: Editora Nacional), p. 198.

${ }^{7}$ Contamine, P. (1984). La guerra en la Edad Media. Barcelona: Labor, p. 228. 
ello se requerían armas de gran tamaño que podían llegar a presentar la altura de un hombre. Este instrumento dio renombre a los arqueros ingleses en toda Europa. Como contrapunto, en la península Ibérica apenas sí tuvo trascendencia, prefiriéndose el manejo de arcos simples (vid. fig. 1). El arco largo se empleó en contadas ocasiones en territorio hispano, siendo probablemente la más popular la participación de longbowmen ingleses en la Primera Guerra Civil castellana (1366 1369) bajo el mando de Eduardo de Inglaterra, partidario del monarca reinante Pedro $I^{8}$.

En lo que concierne a las ballestas parece que su procedencia se vincula con China entre los siglos VI y V a.C., ya que en estas fechas comienza a documentarse como parte de los ajuares funerarios de algunas tumbas ${ }^{9}$. En Roma debieron existir modelos de mano ligados a la caza, pero lo que Vitrubio denomina en su $\mathrm{De}$ Architectura como ballista hace referencia a otro tipo de maquinaria de guerra de compleja construcción utilizada, fundamentalmente, para lanzar piedras ${ }^{10}$. Gracias a La Alexiada, redactada por la princesa bizantina Ana Comneno, podemos saber que en la zona oriental del Imperio romano su uso debió perderse puesto que los bizantinos la desconocían. Ana Comneno, que escribe su obra en el marco de la I Cruzada (siglo XI), dice que es un arco bárbaro totalmente desconocido para los griegos. A continuación describe su forma de uso para acabar mencionando que su efecto parece ser propio del demonio y quien sufre su golpe, muere ${ }^{11}$.

Respecto a su uso bélico en la Europa medieval nos es conocido gracias a la documentación. El papado prohibió el arma en las guerras entre cristianos en el

${ }^{8}$ Esta contienda entre Pedro I, secundado por los ingleses, y su hermanastro Enrique de Trastamara, ayudado a su vez por los franceses, se saldaría con la victoria final de los Trastamaras. Con anterioridad, en 1367, unos 5500 arqueros ingleses demostraron su efectividad en la batalla de Nájera frente a los ballesteros franceses, del mismo modo que el arco inglés se mostró superior durante la Guerra de los Cien Años (vid. fig. 3).

${ }^{9}$ El invento del arma se atribuye a un hombre llamado Chi'in a mediados del siglo VI a. C. Después de que Chi'in inventase la ballesta, tres magnates locales tuvieron noticia de ello y por mediación suya el invento acabaría llegando a manos del gobernador del estado de Ch'u, en la zona central del sur de China. La narración de los hechos se recoge en los Anales de primavera y otoño de Wu y Yüeh. La referencia se tomó de Mc NeILL, W. H. (1988). La búsqueda del poder. Tecnología, fuerzas armadas y sociedad desde el 1000 d. C. Madrid: Siglo veintiuno editores, p. 40 en notas a pie de página.

${ }^{10}$ El arma descrita para el lanzamiento de flechas es la catapulta. Vitrubio (2004). Los diez libros de Arquitectura. Madrid: Alianza, pp. 383 - 386.

11 Ana Comneno. La Alexiada. (ed. preparada por Díaz Rolando, E. (1989). Sevilla: Universidad), p. 416. 
marco del II Concilio de Letrán (1139) castigando su uso con anatema. En el año 1097, bajo el pontificado de Urbano II, ya había sido condenada su utilización por considerarla, como los bizantinos, un arma diabólica ${ }^{12}$. Pese a todas las prohibiciones sabemos bien que los monarcas europeos emplearon cuerpos de ballesteros en sus ejércitos, como sucede en el caso de Ricardo Corazón de León en Inglaterra o Felipe Augusto en Francia ${ }^{13}$. El propio rey inglés sufrió una herida de ballesta en 1199 en el sitio francés de Chêlus que le causó la muerte. Incluso el papado llegó a emplear en ocasiones compañías de ballesteros. En los reinos cristianos peninsulares estas armas formaron parte del equipo básico de infantería desde el siglo XII. Durante mucho tiempo se creyó que las ballestas podían haber sido introducidas en la Península por los cruzados europeos con ocasión de la batalla de las Navas de Tolosa (1212). Sin embargo, la iconografía retrasa esa fecha hasta el siglo XI cuando aparecen en las pinturas de la iglesia de San Baudelio de Berlanga (Soria) y en 1086 en el Beato de Burgo de Osma ${ }^{14}$.

Este armamento fue empleado tradicionalmente por la infantería, el extracto social más bajo del ejército, aunque también existen arqueros y ballesteros de a caballo $^{15}$. Las flechas solían transportarse colgadas al hombro en un carjaj o aljaba, una especie de caja portátil. Aunque su finalidad es la misma, el sistema de carga y la velocidad de tiro eran diferentes. Los arcos demandaban de muchos años de práctica para lograr un disparo eficaz y desarrollar la fuerza suficiente en los dedos para tensarlo. La ballesta, por su parte, una vez cargada correctamente, del modo que más adelante se explicará, únicamente requería colocar la flecha en posición de

${ }^{12}$ Lillo CARPiO, P. A. (1987). "Notas sobre la ballesta y el cuadrillo en la Baja Edad Media". En Abellán Pérez, J. et alii (eds.). Homenaje al profesor Juan Torres Fontes T. I. Murcia: Universidad de Murcia: Academia Alfonso X el Sabio, p. 871.

${ }^{13}$ VARA ThORBECK, C. (1999). El lunes de las Navas. Jaén: Universidad, p. 225.

${ }^{14}$ La introducción del arma en el contexto de batalla de Las Navas de Tolosa fue defendida entre otros por Guerrero Lovillo, J. (1949). Las Cantigas. Estudio arqueológico de sus miniaturas. Madrid: CSIC, p. 155, aunque este autor también hizo hincapié en no olvidar el papel que los musulmanes pudieran haber tenido en su difusión. En cuanto a su presencia ya en el siglo XI es recogida por A. Soler del Campo en su tesis doctoral. Soler Del CAMPO, A. (1994). La evolución del armamento medieval en el reino castellano - leonés y al - Andalus (S. XII - XIV). Madrid: Servicio de Publicaciones del E.M.E., p. 66.

${ }^{15}$ La nobleza despreció tradicionalmente el empleo de arcos y ballestas por considerar la muerte bajo su disparo indigna. Los miembros de este estamento eran entrenados desde niños en las artes bélicas y el enfrentamiento cuerpo a cuerpo. Caer en batalla por un arma manejada por las clases bajas no entraba dentro de su concepción de la guerra, puesto que no dejaba posibilidad alguna de defensa. 
disparo y apuntar a un blanco. Era, pues, más efectiva y su potencia de tiro mucho mayor que la de un $\operatorname{arco}^{16}$. El principal inconveniente que presentaba radicaba en la lentitud de carga de las flechas, que obligaba a los ballesteros a necesitar de un tiempo relativamente largo entre disparo y disparo ${ }^{17}$. Por ello era muy frecuente que en los asedios donde se empleaban ballesteros se colocase en la vanguardia un grupo de arqueros o de escuderos a fin de protegerlos entre cada disparo. En el caso de que las ballestas se usasen como mecanismo de defensa de alguna plaza fortificada, los muros de ésta ejercían de parapeto para cargar el arma sin riesgo físico. La carga podía efectuarse de diferentes maneras y éste es el elemento de la ballesta en el que mejor se aprecia su evolución temporal. El sistema de carga más simple consiste en introducir ambos pies en el arco de la ballesta para tensar la cuerda donde se ha dispuesto el proyectil (vid. fig. 4). Avanzado ya el siglo XII empiezan a aparecer ballestas más potentes que requieren de métodos de carga más elaborados. La más común será la ballesta de estribo. Éste es un apéndice normalmente triangular, situado en la zona distal de la pieza. En él el ballestero encajaba el pie para tensar la cuerda mediante el uso de las gafas, unos potentes ganchos de hierro (vid. figs. 3 y 9). Otro sistema de carga es el llamado torno en el que la cuerda se tensa por medio de poleas accionadas por una manivela de torno. $\mathrm{Su}$ potencia es mucho mayor pero resultan muy complejas en su manejo. Son más $\operatorname{tardías}^{18}$.

\section{TIPOLOGÍA DE LAS PUNTAS DE PROYECTIL}

El registro arqueológico suele proporcionar abundantes puntas de proyectil como evidencias de uso de los arcos y ballestas. La fabricación de éstas en metal, hierro fundamentalmente, permite su conservación. Sin embargo el resto del proyectil desaparece con el paso del tiempo. Con ello nos referimos al astil de

${ }^{16}$ Comúnmente se viene considerando que la difusión de la ballesta está directamente relacionada con la evolución del armamento defensivo. La tradicional cota de mallas utilizada por los ejércitos hasta el siglo XII se va a ir viendo sustituida progresivamente por la armadura de placas, ya usada por los romanos, y el casco completo, que se consolidarán definitivamente en los siglos XIII - XIV. Ello hacía necesario un arma más potente capaz de atravesar esas protecciones. Aunque el alcance de tiro de una ballesta no era superior al de un arco largo, la potencia de disparo de aquella conseguía perforar armaduras e incluso, a tenor de las fuentes escritas, escudos. Otra razón para el triunfo militar del uso de ballestas es la ya mencionada facilidad de manejo de éstas frente al arco largo inglés o el compuesto oriental.

${ }^{17}$ Una ballesta permitía únicamente entre 2 y 4 disparos por minuto mientras que un arco podía llegar a dispararse unas 10 ó 15 veces en el mismo intervalo de tiempo.

${ }^{18}$ P. A. Lillo recoge todos estos sistemas con sus correspondientes ilustraciones en LILLO CARPIO, P. A. (1987). Op. cit., p. 875 , figs. 6,7 y 8. 
enmangue elaborado en madera y al emplumado de la pieza, que estabilizaba su capacidad de vuelo. Los únicos vestigios del astil que podemos llegar a reconocer en circunstancias normales son los restos de la madera descompuesta en el interior del tubo de la punta. Al contrario de lo que podamos pensar, lo usual era fabricar los astiles sobre troncos de madera desbastados y no sobre ramas más pequeñas. Los árboles empleados tenían que tener ya cierta edad. Las puntas de proyectil se utilizaban engrasadas con grasa animal, enceradas o cubiertas de aceite con el fin de aumentar su capacidad de penetración.

En este trabajo se pretende ofrecer una clasificación sistemática de los proyectiles recuperados hasta la fecha en el castro. Para efectuar la tipología aquí presentada se ha recurrido a diversas investigaciones, realizadas en los últimos veinticinco años, sobre materiales recuperados en diferentes contextos medievales a nivel europeo, aunque prestando especial atención al ámbito peninsular. El objetivo era establecer una cierta unidad de criterio que permitiera integrar los materiales de Puente Castro en una visión panorámica de los diferentes conjuntos armamentísticos estudiados hasta el día de hoy. Si bien durante mucho tiempo no se prestó especial atención a este tipo de objetos, en la actualidad disponemos ya de varias colecciones de piezas recuperadas y estudiadas en diversas excavaciones. Entre ellas podemos destacar la clasificación que G. Demians realizó en base al equipo militar recogido en las excavaciones del asentamiento fortificado provenzal de Rougiers. La tipificación de los proyectiles, dividida en cuatro grupos, ha sido empleada por los diversos autores que han estudiado este tipo de armamento. Como punto de partida para muchos análisis en el territorio peninsular se encuentra el estudio de A. Soler sobre un conjunto de proyectiles procedentes de los fondos del Museo Arqueológico Nacional o sus primeras observaciones sobre las piezas recuperadas en Alarcos (Ciudad Real). Otras investigaciones interesantes son las llevadas a cabo por L. Rafael en la alcazaba de Mértola (Portugal) o el estudio de los materiales recuperados en las prospecciones efectuadas en el campo de batalla de Las Navas de Tolosa (Jaén), que coordinaron $\mathrm{M}^{\mathrm{a}}$ D. Rosado Llamas y M. G. López Payer ${ }^{19}$. Además de estos estudios con carácter específico se consultaron referencias de yacimientos que han proporcionado este tipo de materiales ${ }^{20}$.

${ }^{19}$ Por proximidad cronológica y semejanzas formales los conjuntos de Alarcos y Las Navas de Tolosa han resultado claves a la hora de analizar nuestras piezas.

20 Demians D'ARchimbaud, G. (1980). Les fouilles de Rougiers (Var). Contribution à l'archéologie de l'habitat rural médiéval en pays méditerranéen, París: Centre National de la Recherche Scientifique, pp. 445 - 447; Soler Del CAMPO, A. (1988). "Aportación al estudio del armamento medieval: un lote de piezas fechadas entre los siglos X - XIII". I Congreso de Arqueología Medieval Española (Huesca 1985). Zaragoza: Diputación General de Aragón, pp. 313 - 
El conjunto recuperado en Puente Castro se ha subdividido en varias categorías morfológicas. En la Edad Media existe una gran variedad formal de proyectiles que podemos ejemplificar en el caso de Alarcos, uno de los yacimientos arqueológicos que mayor número de piezas de este tipo ha aportado. Esta coyuntura se debe a sus especiales circunstancias de destrucción y abandono ${ }^{21}$.

En una punta de proyectil se diferencian dos zonas básicas: el cuerpo u hoja, que también podemos denominar cabeza, y el enmangue. El criterio básico de clasificación empleado aquí es el modo de sujeción del astil a la punta, es decir, el tipo de enmangue. Se han documentado dos modos diferentes de realizarlo, que han dado lugar a dos grandes grupos de piezas: puntas de proyectil pedunculadas y puntas con enmangue tubular ${ }^{22}$. Dentro de estos grupos fueron identificadas diversas categorías en función de algunos rasgos estructurales como el tamaño de la hoja o la sección de ésta. Otros detalles, como la existencia de una cabeza más o menos definida o, en el caso de las piezas tubulares, la presencia de un enmangue abierto en mayor o menor medida, se consideraron irrelevantes a la hora de definir

329; Soler Del Campo, A. (1995). "Catálogo: Puntas de flecha” En Zozaya, J. (ed.). Alarcos '95. El fiel de la balanza. Ciudad Real: Junta de Castilla - La Mancha, pp. 173 - 178; RAFAEL, L. (1999). "Estudo do armamento islâmico procedente da escavação na encosta do castelo e na alcáçova de Mértola". Arqueologia Medieval 6, pp. 123 - 132; Rosado Llamas, Ma D. y LóPez PAYer, M. G. (2001). La batalla de las Navas de Tolosa. Historia y mito. Andujar: Universidad de Jaén, pp. 177 190.

${ }^{21}$ El castillo de Alarcos, defendido por la Orden de Calatrava, se encontraba en pleno proceso de fortificación en el momento en el que se produce la famosa batalla. Alfonso VIII había iniciado además las obras de construcción de una villa de nueva planta. Todo ello es recogido por las fuentes y ha sido atestiguado por las excavaciones de la zona. En 1195 se produce el enfrentamiento directo entre las tropas del rey castellano y el ejército almohade. La batalla se saldó con la victoria final almohade, triunfo que retrasaría un par de décadas el avance cristiano hacia al - Andalus y que retrocedería la frontera hasta el Tajo. La fosa de fundación de la muralla, excavada directamente sobre los estratos ibéricos, se encontraba entonces al descubierto, ya que la obra no había sido finalizada. De este modo acabó convirtiéndose en testigo mudo de la batalla a través de los siglos. No sólo numerosos restos de ésta cayeron en la fosa permaneciendo in situ hasta su descubrimiento, sino que, en algunas zonas, sirvió como improvisado foso de desecho de la contienda donde se arrojaron despojos de las armas, así como abundantes restos humanos y de équidos. La fosa se cubrió con una capa de cal y piedra como medida sanitaria. El posterior derrumbe de la muralla selló estos espacios y sobre éste se dispuso en época bajomedieval un gran basurero. DE JuAn GARCÍA, A., CABAllero Klink, A. y FERnÁndez Rodríguez, M. (1995). "Alarcos medieval. La batalla de Alarcos". En Zozaya, J. (ed.) Op. cit., pp. 41 - 59.

${ }^{22}$ La sujeción de las piezas se reforzaba mediante el enrollado de hilo vegetal, pelo u otros en la zona de unión del astil y la punta. Era frecuente que se tallasen muescas en la madera para acoger ese hilo. Las muescas eran efectuadas de forma cruzada a la veta natural de la madera para evitar su resquebrajamiento. 
tipos, puesto que se trata de aspectos derivados de la fabricación artesanal y en serie de esta clase de objetos y, por tanto, no guardan relación alguna con su funcionalidad.

Las puntas se encontraban en un estado de conservación relativamente bueno aunque, como es lógico, a causa del paso de los siglos y de su enterramiento, se hallaban afectadas por los fenómenos típicos de la corrosión: el desprendimiento de lascas metálicas en superficie y la presencia de concreciones que provocaron aumentos volumétricos en las piezas.

La clasificación es la siguiente:

\section{Grupo I. Puntas de proyectil con enmangue pedunculado}

Componen este grupo diez de las piezas seleccionadas en la muestra, constituyendo aproximadamente el 22,2 \% del total del material analizado. Se trata de moharras con enmangue en espigo o pedunculado, es decir, provistas de un apéndice de longitud variable en función de su estado de conservación. La finalidad de dicho espigo, de sección circular, es servir de elemento de unión entre la cabeza de la pieza y el astil de madera donde se introducía. Resultan las piezas más fácilmente reconocibles pero, en general, las menos numerosas en las excavaciones. Este tipo de objetos habría evolucionado desde los modelos líticos prehistóricos y las puntas de flecha protohistóricas en metal, tendiendo a desaparecer a medida que avanza la Edad Media, probablemente en relación con el empleo masivo de ballestas potentes que requieren de proyectiles de envergadura ${ }^{23}$. Se fabricarían en una sola pieza a partir de pequeñas barras de hierro forjado, modelando la cabeza y el espigo mediante martillado. En este grupo podemos efectuar distinciones en base al tamaño del cuerpo de las piezas y a la sección de éste.

Tipo I.1: Puntas de proyectil pedunculadas de cuerpo corto (vid. fig. 6). Bajo este epígrafe se adscriben ocho moharras, de desarrollo piramidal y secciones variables -en cuatro de las piezas la sección es triangular (tipo I.la) mientras que en el resto es cuadrangular (tipo I.1b)-, sin que podamos atribuir una razón bélica a

${ }^{23}$ En lo que respecta a su funcionalidad es difícil distinguir cuál era y únicamente se pueden plantear hipótesis como la de $\mathrm{M}^{\mathrm{a}} \mathrm{D}$. Rosado Llamas y M. G. López Payer, que sugieren que este tipo se usase para atravesar cotas de malla debido a su aguda punta, descartando también el poder determinar la clase de arma que las disparó. RosAdo LlAMAS, M ${ }^{a}$ D. y LÓPEZ PAYER, M. G. (2001). Op. cit., pp. 187 y 188. 
este fenómeno ${ }^{24}$. La longitud media total conservada de las piezas es de $4,4 \mathrm{~cm}$ resultando, por tanto, sensiblemente menor a la medida de los elementos recuperados en Alarcos y Las Navas -en torno a los $6 \mathrm{~cm}$ aproximadamente-.

Estas puntas pertenecen a un tipo muy común, conocido tanto en los reinos cristianos como en al - Andalus, cuyo rasgo fundamental radica en la presencia de una cabeza maciza. Ésta aumenta el peso de la pieza incrementando así su capacidad de impacto y eficacia. El ejemplo medieval más antiguo de una punta de este tipo lo documentó A. Soler en el asentamiento islámico de Calatalifa (Madrid), en una pieza datada entre los siglos X - XI. La diferencia con los ejemplares aquí presentados estriba en la presencia de un pedúnculo con sectores circulares de dos tamaños diferentes ${ }^{25}$.

En varios yacimientos europeos se han exhumado proyectiles semejantes a los nuestros. Además de los casos ya citados, tenemos registrada su presencia en contextos almohades vinculados a las alcazabas de Mértola y Silves. Por último cabría citar algún ejemplar más tardío como los recuperados en las excavaciones del castillo de Zuccola (Italia) datados entre los siglos XIII - XIV ${ }^{26}$.

Tipo I.2.: Puntas de proyectil pedunculadas de cuerpo alargado (vid. fig. 7). Únicamente dos de las piezas recuperadas se englobaban dentro de esta categoría. Se trata de los elementos más problemáticos de todos los que nos ocupan, puesto que apenas se han podido documentar paralelos en otras excavaciones, dificultando así su adscripción cronológica y funcional. Morfológicamente se caracterizan por un espigo muy corto en relación al cuerpo y una punta muy alargada de sección bastante irregular, aunque en origen probablemente presentasen la misma sección cuadrada que sus homónimas de otros yacimientos. Esta variación se debería al estado de conservación de las piezas, que resultaron muy afectadas por la corrosión.

${ }^{24}$ Estos mismos tipos se documentan en Alarcos y en Las Navas de Tolosa.

25 Esta punta de proyectil se encuentra depositada en los fondos del Museo Arqueológico Nacional (a partir de ahora M.A.N.) con el número de inventario CM-82/28. SOlER Del CAMPO, A. (1988). Op. cit., p. 316, fig. I, 6.

${ }^{26}$ Rafael, L. (1999). Art. cit., p. 130, fig. 7; Varela Gomes, R. y Santinho Cunha, A. (1991). "Testemunhos arqueologicos da conquista cristã da Alcáçova de Silves". Boletín de Arqueología Medieval 5, p. 156, fig. 4,1 y 4,2; TomAdin, V. et alii (1992). "Le campagne di scavo al castello di Zuccola in cividale del Friuli". Archeologia Medievale XIX, p. 264, tabla 7,13. 
Un conjunto de puntas de proyectil recuperadas en la excavación del Castro de los Judíos (Puente Castro)...

Su longitud oscila entre los 10 y los $11 \mathrm{~cm}$, lo que en este caso sí las asemeja a otras conocidas, concretamente a las exhumadas en el asentamiento musulmán de Vascos (Toledo), las únicas de las que se han facilitado dimensiones ${ }^{27}$.

A. Soler, en su estudio de 1985 sobre algunas piezas de los fondos del M.A.N., documentó la existencia de dos proyectiles similares, que definió como posibles venablos de hierro ante la falta de paralelos conocidos en ese momento. Tampoco disponía de cronologías precisas, puesto que estas piezas se encontraban depositadas en los fondos del Museo con origen desconocido. El autor consideró que, por su forma alargada, podrían relacionarse con algún tipo de arma arrojadiza; de ahí el nombre de venablo ${ }^{28}$.

P. A. Lillo Carpio redactó un pequeño análisis sobre la ballesta y los cuadrillos en la Baja Edad Media, definiendo piezas análogas -sin especificar su procedencia- como fusiformes por su morfología y asimilándolas con los pasadores para disparar con ballesta descritos por J. Almirante en su Diccionario militar ${ }^{29}$. Les atribuyó una cronología entre los siglos XII y XIV. No obstante, no poseemos ninguna certeza de que ese fuera su uso ${ }^{30}$.

J. A. Gutiérrez González publicó algunas puntas similares procedentes del castillo de Barrios de Luna, al noroeste de la provincia leonesa. Ni en este caso ni en el de los elementos recuperados en Vascos, anteriormente citados, los autores definieron estos objetos de un modo particular ${ }^{31}$.

Para finalizar este apartado, hemos de añadir la localización de piezas morfológicamente muy similares fuera del ámbito medieval, en la ciudad romana de Conimbriga (Portugal) ${ }^{32}$. Constituyen un subgrupo de diez elementos cuyas longitudes son, en algunos casos, mayores que las presentadas aquí. Fueron

27 IzQuierdo Benito, R. (1999). Vascos: la vida cotidiana en una ciudad fronteriza de al Andalus. Toledo: Junta de Comunidades de Castilla La Mancha, pp. 144, fig. 88 y 145, fig. 89.

${ }^{28}$ Soler Del CAMPO, A. (1988). Art. cit., p. 317, fig. II y p. 324.

29 Almirante, J. (1989). Diccionario militar. Madrid: Ministerio de Defensa, p. 837.

${ }^{30}$ Lillo CARPiO, P. A. (1987). Art. cit., p. 876.

31 Gutiérrez GonzÁlez, J. A. (1985). Poblamiento antiguo y medieval en la montaña central leonesa, León: Institución Fray Bernardino de Sahagún, p. 74.

32 Moutinho Alarçao, A. y Da Ponte, S. (1979). Fouilles de Conimbriga. Vol. VII: Trouvailles diverses. Conclusions générales. En Alarçao, J. y Etienne, R. (dirs.). Fouilles de Conimbriga. París: Musée Monographique de Conimbriga, láminas XVIII - XIX. 
identificadas por sus investigadoras, A. Moutinho Alarçao y S. Da Ponte, como pilum catapultarium, es decir, proyectiles para ser lanzados con catapulta, máquina de guerra latina a la que ya tuvimos ocasión de aludir en páginas anteriores. Algunas de ellas se dataron entre los siglos II y III d. C., lo que nos lleva a plantear si no nos hallamos ante un tipo de punta usada ya desde la Antigüedad, cuya configuración se mantuvo a lo largo de la Edad Media variando su empleo, tal vez, por el de proyectil de arco o ballesta. A modo de hipótesis es factible pensar que su importancia fuese disminuyendo con el paso de los siglos en beneficio de otras tipologías y por ello sean elementos no tan fácilmente localizables en el registro arqueológico como el resto.

\section{Grupo II. Puntas de proyectil con enmangue tubular (vid. fig. 8)}

Componen este grupo 35 piezas, aproximadamente el 77,7 \% del total de proyectiles recuperados en la campaña de 2005. Se trata de puntas alargadas caracterizadas por una cabeza piramidal de sección cuadrangular y un cubo tubular donde se insertaría un astil de madera. La eficacia de estos proyectiles reside en la fuerza de impacto de su punta maciza, puesto que no disponen de filos cortantes. Su longitud media está en torno a los $8-9 \mathrm{~cm}$, asimilándose así a los ejemplares recuperados en otras excavaciones.

La mayoría de estas piezas presentan un leve ensanchamiento central que realza la forma piramidal de la cabeza. A. Soler pone este rasgo morfológico en relación con el hecho de que este tipo de útiles sean antecedentes de los dardos de ballesta bajomedievales $^{33}$. En el siglo XII la ballesta se hallaba en plena difusión a lo largo

33 Los dardos se diferencian claramente a través de su cabeza, que es mucho más pesada y marcada que en épocas anteriores y suele presentar sección triangular. La longitud del enmangue tubular ocupa en la mayoría de casos la mayor parte de la extensión de la pieza. Estamos ante puntas de gran contundencia pensadas para penetrar en superficies duras sin encontrar demasiados impedimentos. Resultan además más eficaces porque al ser más pesadas y lentas en el vuelo, pierden mucha menos energía en una distancia dada. Algunos ejemplos los hallamos en: DE LuCA, D. (2003). "Le armi da tiro nella rocca di Campiglia marittima. Frecce per arco e dardi per balestra". En Bianchi, G. (coord.). Campiglia. Un castello e il suo territorio, Vol. II: Indagine archeologica. Florencia: all' Insegna del Giglio, p. 405, tabla I, 6-12 y p. 408, tabla II, 13-24, o en Rougiers donde G. Demians los agrupó en su popular clasificación como "tipo 4" (DEmiANS, G. (1980). Op. cit., p. 446, fig. 426, 21 35). En la Península podríamos poner el ejemplo cercano de los hallazgos en el castillo de Ponferrada (León) recogidos en Luengo MartíneZ, J. Ma (1980). El castillo de Ponferrada y los templarios, León: Nebrija, lámina XXIV - D.

Es usual denominar a las contundentes saetas bajomedievales, claramente empleadas como proyectiles de ballesta, con el nombre de "dardos" o "cuadrillos". Otro tipo de terminología menos usual pero que también se vincula a las ballestas es la recogida por J. Almirante en su Diccionario 
de la península Ibérica pero aún no había alcanzado la potencia de los modelos bajomedievales. Sería posible pensar que nos encontrásemos en una fase "de transición" donde estos objetos pudieron jugar un papel de proyectiles polivalentes, como opina el propio A. Soler ${ }^{34}$.

El sistema de fabricación sería sencillo. Se tomaban barras de hierro forjado con una sección más o menos cuadrangular y a partir de ahí se elaboraban las puntas en una sola pieza. El enmangue tubular se conseguía de dos modos: la perforación en caliente o el enrollado de la zona inferior de la barra de hierro. El más usado, a tenor de los investigadores, sería el segundo, empleado también en nuestro caso. Consistía en martillar esa zona para conseguir una superficie plana que, posteriormente, se enrollaba hasta lograr el tubo. Esto explicaría por qué los cierres de las piezas son tan diversos, también en nuestros proyectiles. Algunos tienen el tubo completamente cerrado presentando sólo leves líneas de unión; otros alternan sectores abiertos y cerrados y, en ciertos casos, presentan gran parte del enmangue abierto. El astil de madera se fijaría a presión en el momento de cerrar el cubo de la pieza. En ocasiones, aunque no es el caso de Puente Castro, el astil se aseguraba en el tubo mediante el uso de pequeños clavos ${ }^{35}$.

Cronológicamente este tipo alcanzó gran difusión temporal, puesto que lo documentamos desde los siglos X - XI, en los contextos islámicos de Calatalifa y Vascos, hasta finales del siglo XII y principios del XIII, caso de Alarcos, Las Navas de Tolosa o Rougiers, donde se corresponde con el tipo $3 b^{36}$.

militar y que él agrupa bajo el calificativo genérico de "lances". Se trata de los términos "pasador", ya mencionado, "vira", "virote" y "viratón". Todas ellas se definen como saetas muy agudas. Los tres últimos términos, pertenecientes a la misma familia, parece que habrían aludido también a un pedazo de cuero que cubría la palma de la mano y se aseguraba en el pulgar para que los ballesteros no se hiciesen daño al armar la ballesta. Almirante, J. (1989). Op. cit., pp. 837 y 1063.

34 Soler Del CAMPO, A. (1995). Art. cit., p. 175.

35 Caillaud, F. (1987). "Scribla: le matériel métallique d'un site calabrais fortifié". En Barral i Altet, X. (ed.) Artistes, artisans, et production artistique au Moyen Age, Vol. II. Commande et travail. París: Picard, p. 312.

${ }^{36}$ Las piezas se localizan respectivamente en: SOLER Del CAMPO, A. (1988). Art. cit., p. 321, fig. IV, 1-2; IzQUIERDo BENITO, R. (1979). "Excavaciones en la ciudad hispano - musulmana de Vascos. Campañas 1975 - 1978", Noticiario Arqueológico Hispano 7, p. 361, fig. 54,5; SOlER Del CAMPO, A. (1995). Art. cit., p. 175; Rosado Llamas, M a D. y LóPez Payer, M. G. (2001). Op. cit., p. 89, fig. 50; DEMIANS, G. (1980). Op. cit., pp. 446, fig. 426, 12 - 20. 


\section{CONTEXTO ESTRATIGRÁFICO}

Para finalizar con esta primera aproximación al utillaje bélico del cerro, es necesario plantear el por qué de su presencia en él. Aunque aquí sólo se haya tomado una muestra de materiales, un primer registro de todos los elementos recuperados revela que las puntas de proyectil se concentran en el recinto elevado, presumiblemente la fortificación del cerro. En lo que respecta a la campaña de 2005, los instrumentos recogidos se adscriben a la segunda fase de ocupación del asentamiento, iniciada en el siglo XII, correspondiéndose morfológicamente, como ya hemos visto, con materiales de esta época.

El contexto espacial donde se localizaron comprende varios ámbitos, si bien se concentraban mayoritariamente en la zona norte del sector excavado: ${ }^{37}$

a) siete de ellas se recuperaron en la $U . E$. 1 , en el nivel superficial, mezcladas con restos contemporáneos.

b) nueve piezas se recogieron agrupadas en una misma zona, dentro de la $U$. E. 3 , relleno de tierra parda con abundantes restos arqueológicos.

c) veinte proyectiles se exhumaron vinculados a la $U . E .4$, correspondiente a un nivel de derrumbe de techumbres, donde el abundante material arqueológico relacionado con estructuras de habitación se encontraba mezclado con los restos de las tejas.

d) una punta se recuperó en la $U$.E. 6, formando parte del relleno de una fosa de la cimentación U. E. 102, donde apenas se recogió material de ningún tipo.

e) una punta más se localizó en la U.E. 13 como parte de la preparación del suelo U. E. 110 con abundante ceniza y material arqueológico.

f) seis piezas se hallaron en la $U . E .18$, asociadas a un estrato formado por adobes procedentes bien de suelos, derrumbes de paredes o ambos.

g) el último proyectil se recuperó en la $U$. E. 117, formando parte de la fosa de colmatación del pavimento U. E. 17 perteneciente a la primera fase de ocupación. En esta fosa se halló abundante material arqueológico.

${ }^{37}$ Las estratigrafías se han tomado de MARTínEZ PeÑín, R. (2006). Op. cit., pp. 49 - 51. 
Las puntas de proyectil son uno de los elementos con más peso dentro del ajuar metálico exhumado, no sólo en esta campaña de 2005. Sin embargo, no alcanzan un volumen tal que nos haga pensar en restos del asedio a la fortaleza del cerro en 1196 , lo que parece confirmar su restringida distribución espacial ${ }^{38}$. No obstante, como su funcionalidad bélica no puede ser discutida, así como tampoco su exclusiva localización, ya mencionada en líneas anteriores, en este recinto elevado, sería más plausible pensar que su presencia se vincule con la guarnición existente en el cerro encargada de las labores defensivas de éste, emplazado en un lugar estratégico de acceso y control de la ciudad.

La documentación de apreciables cantidades de escoria entre el material exhumado hace pensar en la existencia de algún taller metalúrgico, quizás de pequeñas dimensiones ${ }^{39}$, encargado de abastecer a los habitantes del cerro de utillaje metálico entre el que se podrían contar las puntas de proyectil recuperadas ${ }^{40}$.

38 pesar de la profusión de fuentes cristianas y judías que lo recogen en sus escritos. No disponemos de testimonios sobre las armas empleadas en el asedio ni cómo se produjo éste. La información dada se limita a establecer los contendientes, la duración del asedio y sus consecuencias. Algunos ejemplos de estas crónicas son: Crónica Latina de los Reyes de Castilla (Ed. de Cabanes Pecourt, M ${ }^{\mathrm{a}}$ D. (1985), Zaragoza: Anubar), p. 29; Crónica de España por Lucas, obispo de Tuy (Ed. de Puyol, J. (1926), Madrid: Real Academia de la Historia), p. 408; Moreno Koch, Y. (1992). Dos crónicas hispanohebreas del siglo XV. Barcelona: Riopiedras, p. 47.

39

Hasta el presente no se han localizado grandes escoriales relacionados con la reducción de mineral lo que excluye la existencia, por el momento, de complejos metalúrgicos importantes. Por otro lado la documentación epigráfica nos ha permitido conocer la existencia entre los habitantes del cerro de un orfebre de nombre Mar Yosef ben' Asís, que probablemente tuvo su taller en el asentamiento y vivió hacia la primera mitad del siglo XI. Esto nos lleva a pensar que no sería descabellado considerar que otras actividades de carácter metalúrgico se llevasen a cabo en el poblado, como por otra parte es común en los asentamientos de cierta entidad de esta época. La inscripción funeraria donde se menciona a este personaje fue estudiada por CANTERA, F. y MILLÁs, F. $\mathrm{M}^{\mathrm{a}}$ (1956). Las inscripciones hebraicas de España. Madrid: C.S.I.C., p. 13.

40 Talleres de este tipo se han registrado en el castillo de Curiel (Peñaferruz, Gijón) o en la fortaleza de Camargo (Cantabria). Ambos registran cronologías que van desde la Alta Edad Media hasta finales del siglo XII y principios del XIII. FernándeZ CALDERÓn, N. y GutiÉRREZ GonZÁlez, J. A. (2003). "Hierro". En Gutiérrez González, J. A. (ed.). Peñaferruz (Gijón). El castillo de Curiel y su territorio. Gijón: vtp editorial, pp. 239 - 241; BoHIGAS RoldÁn, R. (2001). "Evidencias de actividad siderúrgica altomedieval en Cantabria: los hornos del castillo de Camargo (Cantabria). Camargo. Historia y patrimonio. Santander: Ayuntamiento de Camargo, pp. 197 - 209. 


\section{CONCLUSIONES}

Las publicaciones de materiales arqueológicos bélicos en los últimos tiempos cubren un vacío importante en el estudio de la arquería y la ballestería de la Europa medieval, nutrido durante décadas, fundamentalmente, de aquellos aspectos recogidos en la documentación escrita tales como el entrenamiento de la infantería que manejaba estos instrumentos, su despliegue en los asedios o batallas, funcionamiento de las armas, etc. El análisis de los proyectiles en sí, paradójicamente bastante frecuentes en excavaciones medievales, se obviaba.

Este trabajo pretende únicamente integrarse en la miscelánea de estudios que han venido publicándose en relación a conjuntos armamentísticos medievales y que resultan necesarios para establecer tipologías y cronologías relacionadas con éstas.

Las piezas presentadas muestran los tipos formales más característicos en el siglo XII, fecha a la que se adscribe este conjunto, sin que podamos determinar con exactitud su vinculación con el uso de arcos o de ballestas, ambas armas muy difundidas a lo largo de la Edad Media.

La localización en el cerro de este tipo de armamento parece estar relacionada con la existencia de alguna clase de fortificación en el mismo. Ésta debería abastecerse para su defensa de este tipo de objetos.

Uno de nuestros objetivos es llevar a cabo la ampliación de estos planteamientos en el futuro, cuando se aborde el estudio completo del utillaje bélico recuperado en las excavaciones del Castro de los Judíos. 


\section{APÉNDICE DE ILUSTRACIONES}
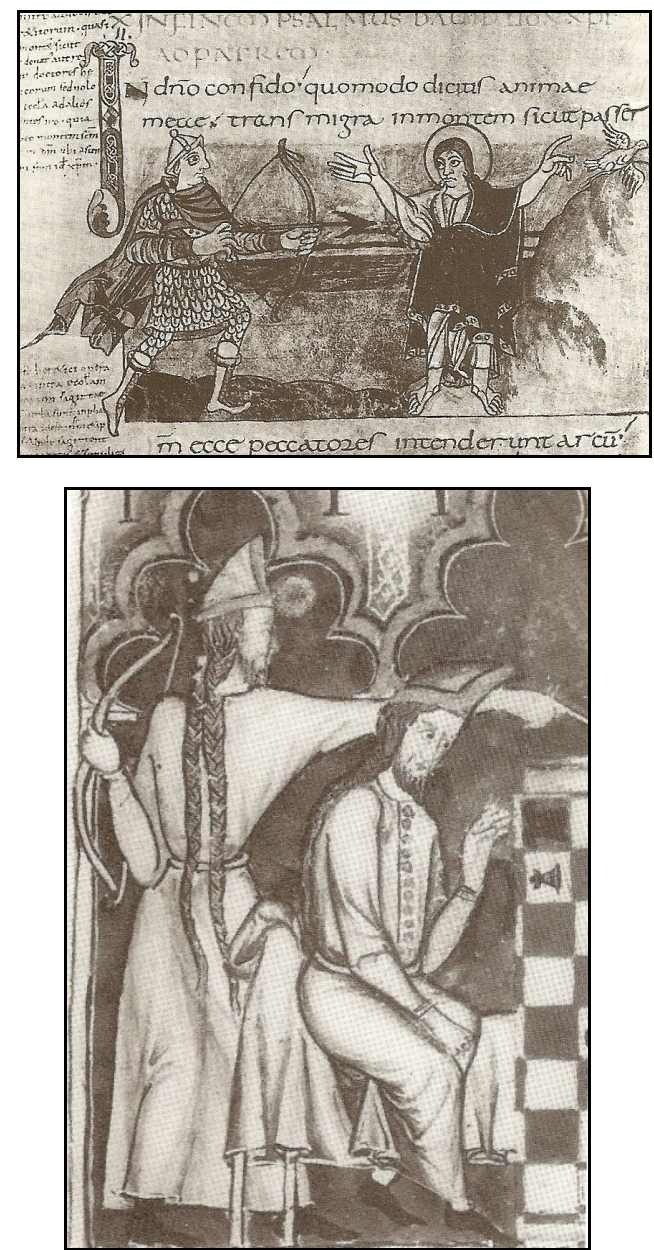

Fig. 2: Arco compuesto. Libro de los Juegos, fol. $11 \mathrm{v}$, de la obra de Alfonso $\mathrm{X}$. En la imagen aparecen dos personajes vestidos y peinados al modo oriental. Uno de ellos porta un arco compuesto donde se aprecia la doble curvatura característica de éste. (Imagen tomada de R. Menéndez Pidal. La España del siglo XIII leída en imágenes, p. 104).
Fig. 1. Arco simple. Salterio franco del siglo IX (Imagen tomada de T. Reuter. "La guerra carolingia y otoniana". En Keen, M. (ed.). Historia de la guerra en la Edad Media, p. 42).

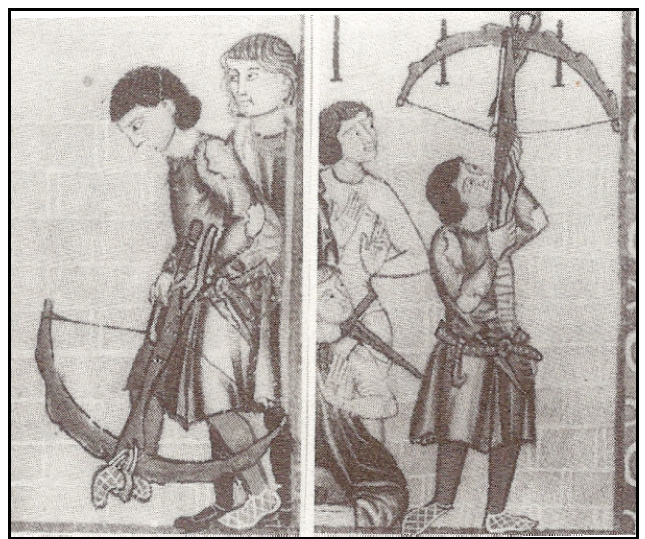

Fig. 3: Ballesta de estribo en dos secuencias: carga del arma y disparo. Cantiga 153 de la obra de Alfonso X. (Imagen tomada de R. Menéndez Pidal. La España del siglo XIII leída en imágenes, 264). 

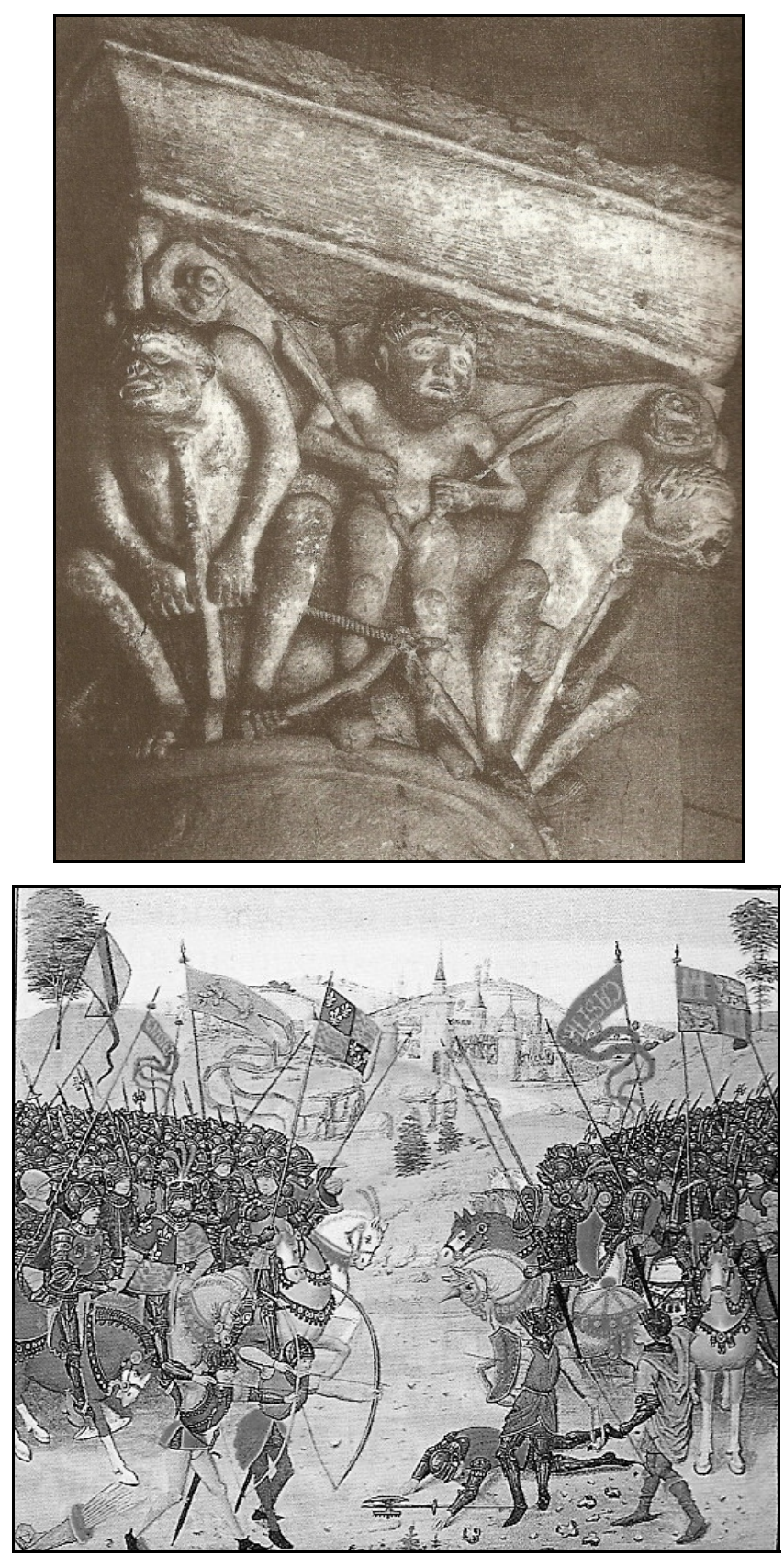

Fig. 4: Demonio tensando una ballesta de dos pies en un capitel de Saint Sernin de Toulouse (fines siglo XI). Simboliza el carácter diabólico del arma. (Imagen tomada de J. Gillingham. "Una era de expansión c. 1020 - 1204". En Keen, M. (ed.): Historia de la guerra en la Edad Media, p. 102).

Fig. 5: Arqueros ingleses empleando el long bow en la batalla de Nájera (1367). (Imagen tomada de las Crónicas de Jean Froissart (ed. a cargo de Cirlot, V. y Ruiz Domenec, J. E.), p. 232). 

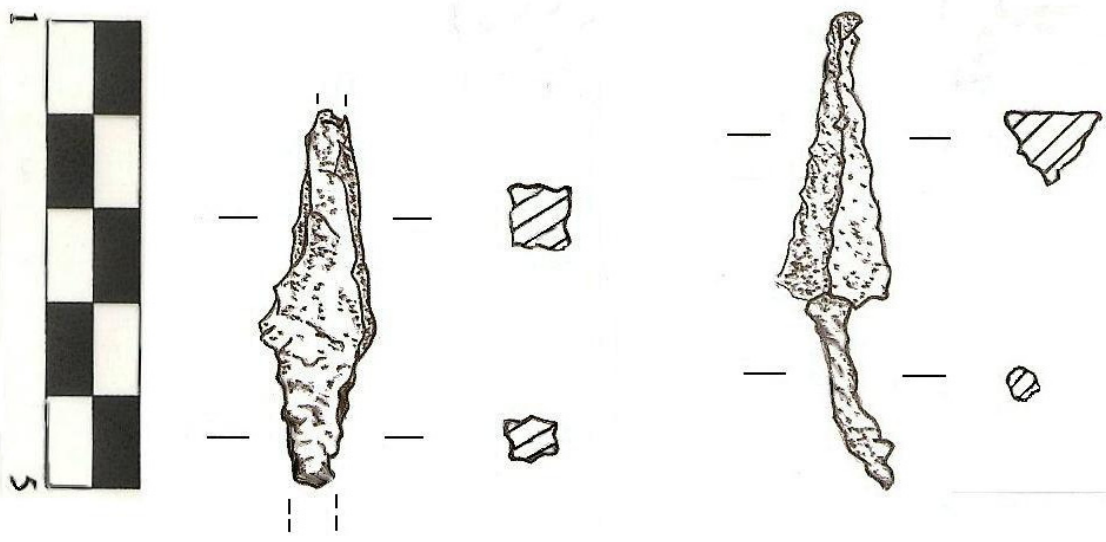

Fig. 6: Ejemplos de puntas de proyectil con enmangue pedunculado recuperadas en el Castro de los Judíos (Puente Castro. León). GRUPO 1. De izquierda a derecha TIPOS I.1a. y 1.1b. (González Castañón, María. 2007).

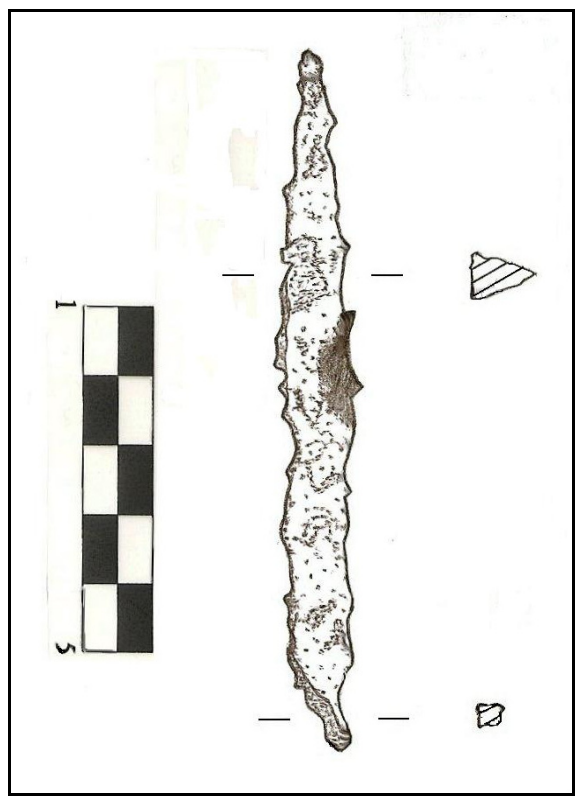

Fig. 7: Ejemplo de punta de proyectil con enmangue pedunculado recuperada en el Castro de los Judíos (Puente Castro. León). GRUPO 1. TIPO I.2. El deficiente estado de conservación de la pieza provoca que su sección presente un aspecto triangular, aunque en origen debió ser cuadrangular como los paralelos documentados en otras excavaciones. (González Castañón, María. 2007) 


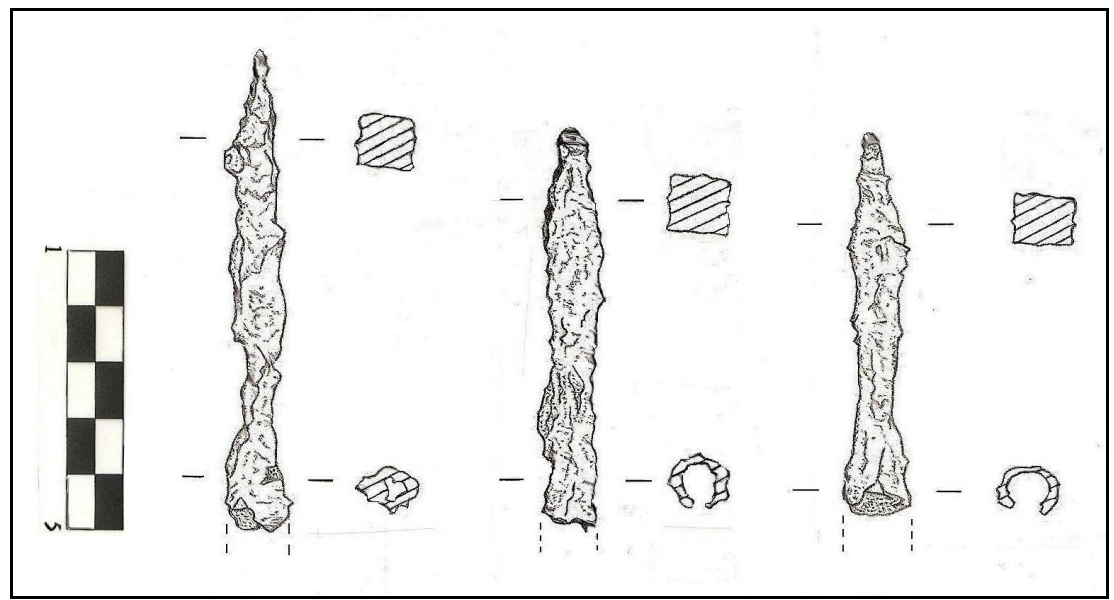

Fig. 8: Ejemplos de puntas de proyectil con enmangue tubular recuperadas en el Castro de los Judíos (Puente Castro. León). GRUPO 2 (González Castañón María. 2007).

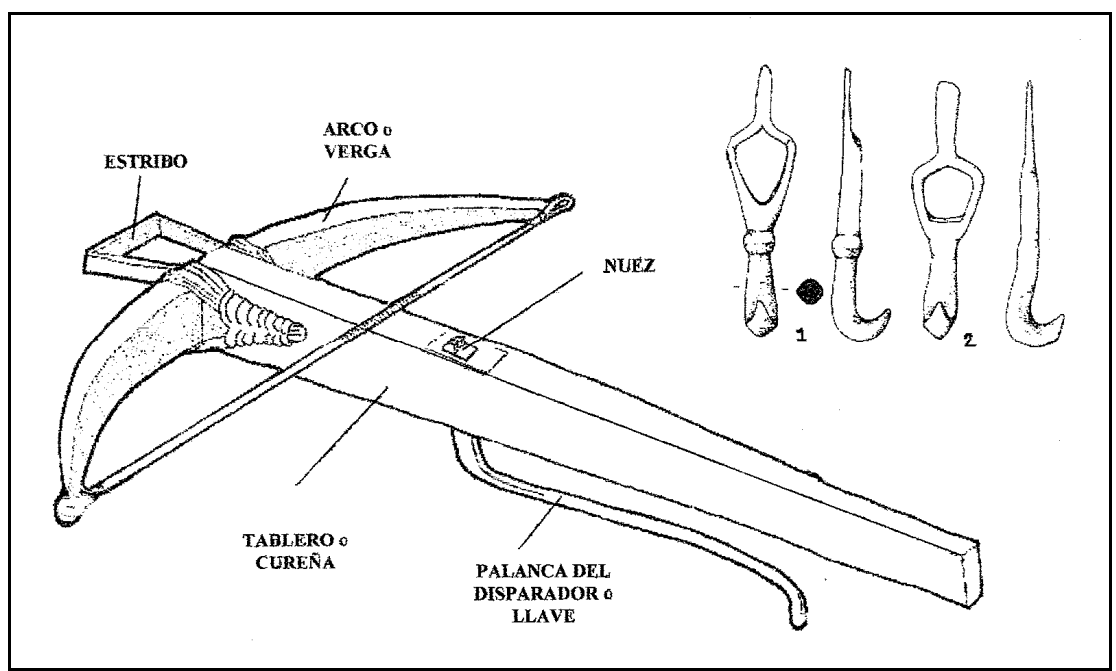

Fig. 9: Esquema de una ballesta donde figuran las partes principales. La "gafa" de la zona superior derecha de la imagen se empleaba enganchada en la cuerda para facilitar el tensado del arma. Una vez colocado el proyectil y tensada la cuerda, ésta se traba con uno de los salientes o uñas que posee la nuez. Por su zona inferior la otra uña queda enganchada con la llave, manteniendo fijo el proyectil. Cuando el extremo de la llave se acciona hacia arriba, la palanca baja y libera la nuez, que gira sobre sí misma disparando el proyectil. (El esquema de la ballesta ha sido tomado de D. de Luca. "Le armi da tiro nella Rocca di Campiglia Marittima. Frecce per arco e dardi per balestra". En Bianchi, G.: Campiglia. Un castello e il suo territorio, VOL. II, p. 400. Los dibujos de las gafas se han tomado de G. Demians. Les fouilles de Rougiers, p. 447. 